http://dx.doi.org/10.32929/2446-8355.2019v28n4p396-407

\title{
ARBORIZAÇÃO URBANA EM UM TRECHO DA ALAMEDA MATO GROSSO, ILHA SOLTEIRA - SP, BRASIL
}

Walter Aparecido Ribeiro Júnior ${ }^{*}$, Beatriz Pereira Sanches ${ }^{2}$, Regina Maria Monteiro de Castilho $^{3}$

\footnotetext{
${ }^{1}$ Engenheiro Agrônomo, Mestrando do Programa de Pós-Graduação em Agronomia da Universidade Estadual de Londrina (UEL), Londrina, Paraná.*E-mail do autor correspondente: junior_agro40@ hotmail.com

${ }^{2}$ Engenheira Agrônoma, graduada pela Faculdade de Engenharia de Ilha Solteira (FEIS - UNESP), Ilha Solteira, São Paulo.

${ }^{3}$ Docente do curso de Agronomia, Faculdade de Engenharia de Ilha Solteira (FEIS - UNESP), Dr ${ }^{\mathrm{a}}$ em Ciências Biológicas (Botânica) pela Universidade Estadual Paulista Júlio de Mesquita Filho/ Instituto de Biociências (UNESP - Botucatu), Ilha Solteira, São Paulo.
}

Recebido: 31/05/2019; Aceito: 21/11/2019

RESUMO: O objetivo do presente trabalho foi avaliar árvores de um trecho da Alameda Mato Grosso, que se localiza defronte ao Passeio Ladário na cidade de Ilha Solteira, São Paulo, Brasil, em primeiro de maio de 2017. Para as avaliações foram levados em consideração critérios paisagísticos, ecológicos, fitossanitários e a situação das raízes de árvores adultas, assim como o calçamento no entorno dos canteiros. Toda avaliação foi visual e utilizou-se de fita métrica para medir o tamanho dos canteiros e da calçada. Foram identificados 14 indivíduos segregados em 5 espécies vegetais e 1 categoria não segregada em espécie (Palmeira não identificada), dispostos em 12 canteiros instalados em 84 metros lineares, apresentando uma média de 0,15 árvores/metro linear. A espécie mais observada no trecho foi Poincianella pluviosa com 50\% de exemplares. Os canteiros não apresentavam formato padrão, sendo que cada um possuía um tamanho em particular, e por haver número de canteiros inferior ao de árvores, algumas foram alocadas no mesmo canteiro, e apenas o nono canteiro apresentou tamanho adequado e recomendado para a arborização. Foram detectados focos de cupins em P. pluviosa e Licania tomentosa, e não foram detectados problemas severos de exposição de raízes, contudo há ocorrência de problemas moderados $(50 \%)$ e severos $(16,66 \%)$ com relação ao quebramento de calçada que podem resultar em problemas para pedestres. A área apresentou baixa diversidade ecológica e, o espaço livre para árvores pode ser melhorado tendo em vista que o calçamento apresenta largura suficiente para a ocorrência da arborização e utilização por pedestres.

Palavras-chave: Floresta urbana. Sustentabilidade. Paisagismo. Cidades.

\section{URBAN ARBORIZATION IN A PART OF ALAMEDA MATO GROSSO, ILHA SOLTEIRA - SP, BRAZIL}

ABSTRACT: The objective of the present work was to evaluate trees of a stretch of Alameda Mato Grosso, which is located in front of the Ladário Promenade in Ilha Solteira, São Paulo, Brazil, on May 1, 2017. For the evaluations were considered, landscape criteria, ecological, 
phytosanitary and the situation of the roots of adult trees, as well as the pavement around the beds. All assessment was visual and a tape measure was used to measure the size of the beds and sidewalk. Fourteen individuals were identified, 5 trees species and 1 non-segregated species category (unidentified palm), arranged in 12 beds installed in 84 linear meters, with an average of 0.15 trees / linear meter. The most observed species in the stretch was Poincianella pluviosa with $50 \%$ of specimens. The beds had no standard format, each of which had a particular size, and because there were fewer beds than trees, some were allocated to the same bed, and only the ninth bed was of adequate size and recommended for afforestation. Termite outbreaks have been detected in P. pluviosa and Licania tomentosa, and severe root exposure problems have not been detected, but there are moderate (50\%) and severe (16.66\%) problems with sidewalk breakage that can result in problems for pedestrians. The area presented low ecological diversity and the free space for trees can be improved considering that the pavement has enough width for the occurrence of afforestation and use by pedestrians.

Key words: Urban forest. Sustainability. Landscaping. Cities.

\section{INTRODUÇÃO}

A agregação de novos espaços à área urbana sem planejamento adequado confere características insalubres à cidade, devido principalmente às ações antrópicas e seus efeitos, provocando a supressão da vegetação para dar vez aos materiais urbanos (LIMA NETO et al., 2010; MARTINS et al., 2011). Dessa forma surgiram inúmeros problemas ambientais como poluição, extinção de espécies vegetais e animais, ilhas de calor, enchentes e inversão térmica devido ao desmatamento e diminuição de áreas permeáveis (INSTITUTO BRASILEIRO DE GEOGRAFIA E ESTATÍSTICA - IBGE, 2018a).

As cidades representam o espaço físico onde ocorrem as relações sociais e também a produção da vida, assim a qualidade ambiental do espaço urbano resulta em benefícios diretos na saúde (física e emocional) e no bem-estar da população devido à interação com o ambiente. Por isso, é de suma importância que haja planejamento adequado para que os recursos naturais possam ser bem empregados pelos cidadãos e também para que o ambiente se torne ou se mantenha saudável (LONDE; MENDES, 2014; ALENCAR; CARDOSO, 2015).

Para Londe e Mendes (2014), os espaços verdes (parques, bosques, jardins, praças arborizadas e árvores viárias) proporcionam diversas soluções benéficas para os mais variados problemas urbanos como filtragem da poluição do ar, redução da velocidade do vento, sombreamento para pedestres, ciclistas, veículos, casas e comércios, além de melhorar a qualidade e vida útil do asfalto, redução do impacto das gotas de chuva, prevenção contra erosão, infiltração de água ao solo melhorando o escoamento procurando reduzir problemas de enchentes, redução da temperatura através da evapotranspiração e mascarar o som promovido por automóveis.

A arborização urbana é definida como o conjunto de áreas públicas e privadas com vegetação predominantemente arbórea que foi implantada ou é remanescente natural que existe em uma cidade, sendo expressa pelas árvores de ruas e avenidas, parques públicos, 
privados e demais áreas verdes (MILANO, 1988). Dentre os locais onde árvores podem ser implantadas e encontradas em uma cidade, existem diferenças entre as escolhidas para compor a arborização viária e a de praças e jardins públicos, e segundo Avrella et al. (2014) existe maior riqueza de espécies no sistema viário.

Contudo, devido à falta de planejamento adequado para a inserção da arborização no meio urbano as árvores são responsabilizadas pelos conflitos existentes nas cidades. A árvore passa a disputar espaços na paisagem com diversos elementos urbanos como as redes de energia e telefonia, cercas elétricas residenciais, fachadas comerciais, casas e calçadas, dessa forma os exemplares arbóreos são removidos com a justificativa de que folhas entopem as calhas, ao quebramento de calçadas pelas raízes, queda de galhos e mudanças e aumento da malha urbana, resultando em condições ambientais difíceis para as árvores remanescentes (SILVA; SOUZA, 2018; SOUZA et al., 2018).

Quando se responsabiliza a árvore pelos conflitos urbanos, é omitido que a mesma não foi escolhida corretamente, tão pouco tratada e manipulada de forma a beneficiar o espaço urbano onde foi inserida. Quando moradores, jardineiros ou o poder público não possuem consciência ambiental suficiente para escolher o porte de árvore correto para o local, levando em considerações suas características de copa, caule, folhas e raízes, não adequam o tamanho de canteiro ou berço ideais para o recebimento da muda, ou escolhem espécies exóticas em relação ao local, os transtornos gerados posteriormente podem resultar em consequências que limitam ainda mais o pensamento do morador em relação ao real benefício da arborização urbana (CABRAL, 2013; SANTOS et al., 2017).

Nesse sentido, o objetivo do presente trabalho foi avaliar visualmente as árvores da Alameda Mato Grosso defronte ao Passeio Ladário na cidade de Ilha Solteira, São Paulo, Brasil, em sua totalidade (raiz, caule, copa) e os elementos do entorno (calçamento).

\section{MATERIAL E MÉTODOS}

\section{Caracterização da área:}

O município de Ilha Solteira se encontra situado na região noroeste do Estado de São Paulo, tem uma população média estimada de 26.582 habitantes, densidade demográfica de $38,42 \mathrm{hab} / \mathrm{km}^{2}$, com latitude $20^{\circ} 25^{\prime} \mathrm{S}$, longitude $51^{\circ} 20^{\prime} \mathrm{W}$ e altitude média de $335 \mathrm{~m}$ apresentando área de unidade territorial de $652,641 \mathrm{~km}^{2}$, possuindo $55,3 \%$ de arborização das vias públicas da cidade (IBGE, 2018b). De acordo com o Sistema Internacional de Köeppen, o clima desta região é do tipo Tropical úmido ( $\mathrm{Aw}$ ), com estação chuvosa no verão e seca no inverno. As temperaturas médias variam de $19,9^{\circ} \mathrm{C}$ em julho até $27,2^{\circ} \mathrm{C}$ em fevereiro e as precipitações médias mensais variam de $0,0 \mathrm{~mm}$ em julho a $302 \mathrm{~mm}$ em dezembro. O período de excedente hídrico estende-se de janeiro a fevereiro, e o de deficiência hídrica, de março a dezembro.

A área avaliada foi um trecho de calçada de $84 \mathrm{~m}$ de comprimente por 3,68 $\mathrm{m}$ de largura da Alameda Mato Grosso em frente ao Passeio Ladário com caminhamento no sentido Avenida Brasil para Avenida Perimetral Sul. A escolha foi feita devido ao fato de estar na 
proximidade de uma agência bancária, restaurantes, clube e residências mantendo um considerável fluxo de pessoas que transitam pelo local diariamente. Outro fator que colaborou para a escolha é a utilização do sombreamento das árvores na rua como forma de estacionamento além do trafego de veículos.

\section{Parâmetros gerais observados:}

Foi realizado vistoria visual em árvores de forma individual, sendo anotados os seguintes dados: Identificação pelo nome cientifico e nome vulgar; situação da calçada em relação ao canteiro e a árvore; situação da raiz, tamanho da área livre em torno da árvore (canteiro); estado fitossanitário (presença ou não de pragas e doenças); presença de podas; presença de fiação elétrica.

\section{Parâmetros específicos observados com relação às raízes:}

A situação das raízes e da calçada foi analisada a partir de uma adaptação de Milano (1988), formando 4 grupos: grupo de raízes não expostas; grupo de raízes com leve exposição (superficial com até $5 \mathrm{~cm}$ ), grupo de raízes com exposição moderada (entre $5 \mathrm{~cm} \mathrm{e} 10 \mathrm{~cm}$ acima da calçada) e, grupo de raízes de exposição severa (mais que $10 \mathrm{~cm}$ acima da calçada); o quebramento da calçada foi analisado e para o agrupamento de dados foram formados 3 grupos: quebra leve (rachada mas sem risco de gerar acidentes), quebra moderada (calçada elevada com leve risco de colisão e que dificulta o passeio de pessoas com mobilidade reduzida) e, quebra severa (pode ocasionar acidentes e impede o passeio de pessoas com mobilidade reduzida).

\section{RESULTADOS E DISCUSSÃO}

A área amostral totalizou 84 metros de extensão linear no qual foram avaliados 14 indivíduos totalizando 6 espécies incluídas em 5 famílias botânicas (Tabela 1). Levando-se em consideração apenas as espécies arbóreas, há 0,15 árvores/metro linear ou 150 árvores/km linear, e segundo a Sociedade Brasileira de Arborização Urbana é recomendado que existam pelo menos 100 árvores/ km linear de calçada (PAIVA et al., 2010), nesse sentido a área estudada encontra-se em perfeito acordo com o valor recomendado.

A família mais representativa (Tabela 1) foi Fabacea (Leguminosae) com 8 indivíduos. Há predominância de Poincianella pluviosa (DC.) que representa 50\% do total de indivíduos avaliados, seguido por Licania tomentosa (Benth.) com $22 \%$ de frequência; observa-se que a distribuição das espécies é irregular e a dominância de uma espécie na arborização varia de acordo com a cidade e a região do Brasil, sendo que esse fato é corroborado por Martins et al. (2011) e Silva e Souza (2018). Além disso, Poincianella pluviosa é uma espécie indicada para arborização urbana por manuais técnicos, livros e demais obras cientificas (CEMIG, 2011; SILVA FILHO et al., 2018), levando a crer que a escolha das espécies que compõem a floresta urbana pode estar relacionada a esse fator. Contudo, tendo em vista que a arborização urbana faz parte das gestões governamentais de cada município, essas escolhas podem partir 
do conhecimento, gosto e preferência política de cada gestor, e dessa forma é imprescindível que o conhecimento cientifico e a gestão urbana se complementem e caminhem juntos para que haja melhor realização do espaço urbano (PEREIRA; LOBADA, 2017).

Tabela 1. Identificação das espécies vegetais presentes na área de estudo. Ilha Solteira 2017. Identification of the plant species present in the study area. Ilha Solteira 2017.

\begin{tabular}{|c|c|c|c|c|c|c|}
\hline Nome científico & Nome popular & Família & Origem & Hábito & $\begin{array}{l}\mathrm{N}^{\mathrm{o}} \mathrm{de} \\
\text { indivíduos }\end{array}$ & Freq. \\
\hline $\begin{array}{l}\text { Poincianella } \\
\text { pluviosa }\end{array}$ & Sibipiruba & Fabaceae & $\mathrm{NB}-\mathrm{ER}$ & A & 7 & $50 \%$ \\
\hline Ficus benjamina & $\begin{array}{l}\text { Figueira } \\
\text { benjamim }\end{array}$ & Moraceae & $\mathrm{E}$ & A & 1 & $7 \%$ \\
\hline $\begin{array}{l}\text { Cesalpinia } \\
\text { pulcherrima }\end{array}$ & $\begin{array}{l}\text { Flamboyam- } \\
\text { de-jardim }\end{array}$ & Fabaceae & $\mathrm{E}$ & $\mathrm{ARB}$ & 1 & $7 \%$ \\
\hline $\begin{array}{l}\text { Licania } \\
\text { tomentosa }\end{array}$ & Oiti & Chrysobalanaceae & $\mathrm{NB}-\mathrm{ER}$ & $\mathrm{A}$ & 3 & $22 \%$ \\
\hline Mangifera indica & Manga & Anacardiaceae & $\mathrm{E}$ & A & 1 & $7 \%$ \\
\hline $\begin{array}{ll}\text { Palmeira não } \\
\text { identificada }\end{array}$ & Palmeira & Arecaceae & - & $\mathrm{P}$ & 1 & $7 \%$ \\
\hline
\end{tabular}

Nota: Origem: N: Nativa; E: Exótica; NB - ER: Nativa do Brasil, Exótica da Região de Ilha Solteira. Clas. Bot.: A: Árvore; ARB: Arbusto; P: Palmeira. Note: Source: N: Native; E: Exotic; NB - ER: Native of Brazil, Exotic of the Region of Ilha Solteira. Clas. Bot.: A: Tree; ARB: Shrub; P: Palm tree.

Fonte: Autoria própria. Own authorship.

Os 12 canteiros avaliados representam o espaço livre em torno da árvore, para o desenvolvimento das raízes e como área permeável para absorção de água, contudo não possuem padrão no formato, sendo todos de tamanhos desiguais (Tabela 2).

Tabela 2. Área dos canteiros como espaço livre em torno das árvores e área permeável. Ilha Solteira 2017. Area of beds as free space around trees and permeable area. Ilha Solteira 2017.

\begin{tabular}{cccc}
\hline $\begin{array}{c}\text { Identificação do } \\
\text { Canteiro }\end{array}$ & Comprimento $(\mathrm{m})$ & Largura $(\mathrm{m})$ & Área $\left(\mathrm{m}^{2}\right)$ \\
\hline 1 & 1,44 & 1,42 & 2,04 \\
2 & 1,14 & 1,27 & 1,45 \\
3 & 1,50 & 1,38 & 2,07 \\
4 & 1,57 & 1,64 & 2,58 \\
5 & 0,79 & 0,80 & 0,63 \\
6 & 1,54 & 1,45 & 2,23 \\
7 & 1,48 & 1,45 & 2,15 \\
8 & 1,69 & 1,48 & 2,50 \\
9 & 2,03 & 1,86 & 3,78 \\
10 & 1,04 & 1,13 & 1,18 \\
11 & 1,41 & 1,14 & 1,61 \\
12 & 1,50 & 1,43 & 2,14 \\
\hline
\end{tabular}


Por haver número de canteiros inferior ao de árvores, algumas plantas encontram-se instaladas no mesmo espaço, isso resulta em competição de raízes e copa por área livre, nutrientes e água (Figura 1). Nos canteiros 2 e 7 foram detectadas essas interações competitivas, e faz-se necessário a supressão dos indivíduos excedentes para mitigar problemas que podem ocorrer no futuro como a queda de algum exemplar. Como comentado por Amaral et al. (2015) as espécies necessitam de condições onde possam ocorrer de forma livre sem interferência ao seu desenvolvimento com competição mínima por água, luz e espaço.

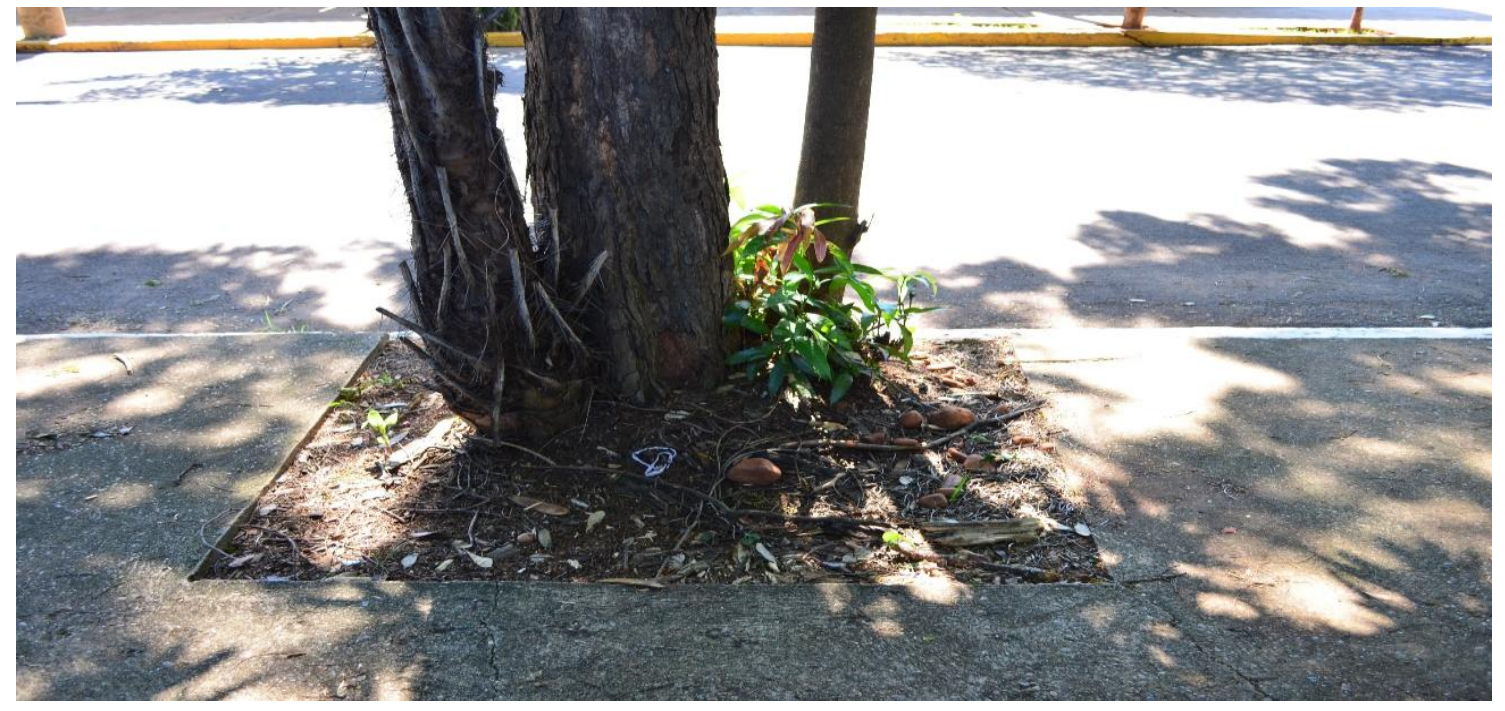

Figura 1. Canteiro 7 com mais de um indivíduo, competição de raízes por área livre, nutrientes e água. Ilha Solteira, 2017. Bed 7 with more than one individual, competition of roots for free area, nutrients and water. Ilha Solteira, 2017.

Fonte: Autoria própria. Own authorship.

A largura e o comprimento dos canteiros não seguem padrão, sendo o canteiro de menor tamanho com $0,63 \mathrm{~m}^{2}$, o de maior tamanho com 3,78 $\mathrm{m}^{2}$ e a média entre eles de 2,03 $\mathrm{m}^{2}$. De acordo com o Decreto $n^{\circ} 45.904 / 05$ no Art. $7^{\circ}$ : "A faixa de serviço localizada em posição adjacente à guia, deverá ter, no mínimo, $70 \mathrm{~cm}$ (setenta centímetros) e ser destinada à instalação de equipamento e mobiliário urbano, à vegetação e a outras interferências existentes nos passeios...”, já a NBR 9050/2015 diz que as rotas para caminhamento necessitam ser acessíveis e possuir área de circulação e manobra de até $1,80 \mathrm{~m}$, sendo no mínimo $1,20 \mathrm{~m}$. Somando-se os $70 \mathrm{~cm}$ o calçamento deve ter no mínimo $1,90 \mathrm{~m}$ para assegurar a mobilidade nas vias e a existência de equipamentos e vegetação; para o tamanho de canteiros é possível encontrar diferentes propostas e sugestões, sendo que o Manual Técnico de Arborização Urbana de São Paulo (SÃO PAULO, 2011) indica larguras mínimas para o canteiro em relação ao diâmetro da copa: para árvores de copa pequena (média de $4 \mathrm{~m}$ de diâmetro) necessário canteiros com no mínimo $2 \mathrm{~m}^{2}$ de área permeável, e árvores de copa grande (média de $8 \mathrm{~m}$ de diâmetro) com no mínimo $3 \mathrm{~m}^{2}$, sempre respeitando as exigências da legislação vigente (SÃO PAULO, 2011).

Conforme os dados obtidos (Tabela 2) e as recomendações, percebe-se que apenas o canteiro 9 encontrava-se em acordo, pois foi o único que totalizou uma área equivalente ou superior a $3 \mathrm{~m}^{2}$, os demais estavam em desacordo, apresentando área menor do que o 
recomendado. Todos os indivíduos avaliados se encontravam vivos na época da avaliação, aparentemente bem estabelecidos no local apesar da exposição de raízes (Tabela 3 e Figura 2).

Tabela 3. Situação de raízes com relação à intensidade de exposição. Ilha Solteira 2017. Root situation with respect to the intensity of exposure. Ilha Solteira 2017.

\begin{tabular}{llll}
\hline Exposição de raízes & $\mathrm{N}^{\circ}$ Canteiro & Número de árvores & Espécie \\
\hline Não exposta & $5 / 6 / 8 / 10 / 11$ & 6 & $\mathrm{C} / \mathrm{P} / \mathrm{P} / \mathrm{P} / \mathrm{L} / \mathrm{P}$ \\
Leve & $1 / 3$ & 2 & $\mathrm{P} / \mathrm{P}$ \\
Moderado & $2 / 4 / 7 / 9$ & 4 & $\mathrm{~F} / \mathrm{P} / \mathrm{P} / \mathrm{L}$ \\
Severo & - & - & - \\
\hline
\end{tabular}

Notas: Espécie: C: Caesalpinea pulcherrima; F: Ficus benjamina; L: Licania tomentosa; P: Poincianella pluviosa. Não exposta; leve exposição (superficial com até $5 \mathrm{~cm}$ ), exposição moderada (entre $5 \mathrm{~cm}$ e $10 \mathrm{~cm}$ acima da calçada), exposição severa (mais que $10 \mathrm{~cm}$ acima da calçada). Notes: Species: C: Caesalpinea pulcherrima; F: Ficus benjamina; L: Licania tomentosa; P: Poincianella pluviosa. Not exposed; slight exposure (superficial up to $5 \mathrm{~cm}$ ), moderate exposure (between $5 \mathrm{~cm}$ and $10 \mathrm{~cm}$ above the sidewalk), severe exposure (more than $10 \mathrm{~cm}$ above the sidewalk).

Fonte: Adaptado de Milano (1988). Adapted from Milano (1988).

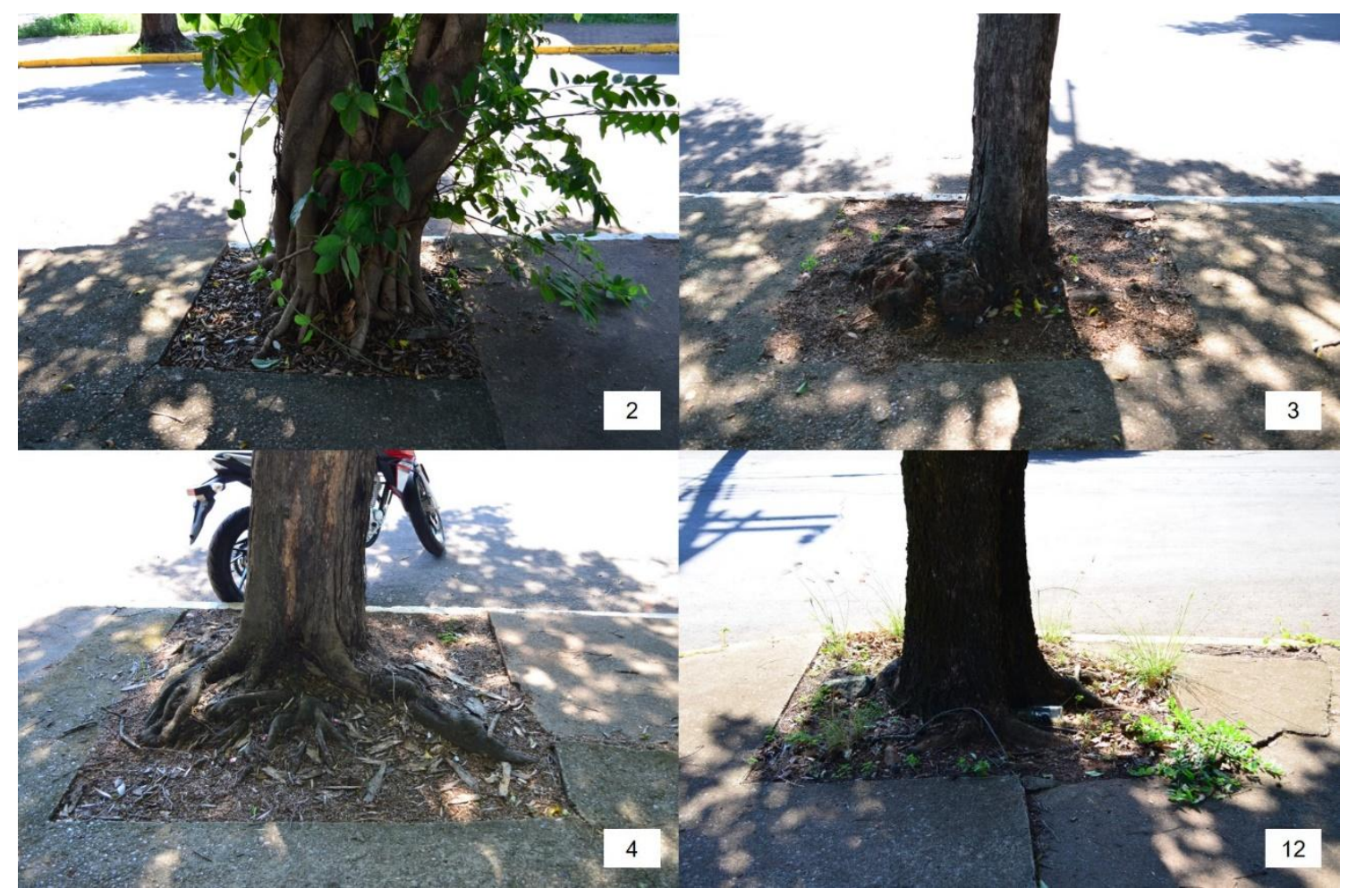

Figura 2. Situação de raízes, com relação a intensidade de exposição nos canteiros 2, 3, 4 e, 12. Ilha Solteira 2017. Root situation, in relation to intensity of exposure in flower beds 2, 3, 4 and, 12. Ilha Solteira 2017.

Fonte: Autoria própria. Own authorship.

No estudo realizado, observa-se que a área para crescimento horizontal das raízes é limitada, sendo esse fato corroborado por Costa (2018), que afirma que isso ocorre devido a compactação do solo para implantação da rede de esgoto e água, além do asfalto e calçadas. As rupturas causadas por tal fato dificultam o trafego de pessoas, principalmente as com mobilidade reduzida e podem acarretar em acidentes a pessoas mais desatentas ou idosos. 
Lima Neto et al. (2010) encontraram os mesmos problemas com relação as raízes em trabalho sobre a influência da arborização urbana na acessibilidade na cidade de Curitiba - PR - Brasil, sendo que o Ligustro (Ligustrum lucidum Ait.) favoreceu a ocorrência do quebramento de calçada e conflito na passagem de pedestres. Outros fatores levantados pelos mesmos autores estão relacionados ao manejo inadequado na produção de mudas em viveiros e às árvores já instaladas no sistema viário. Para eles é necessário que haja melhor planejamento e melhores formas de organização dos sistemas de produção de mudas, instalação das árvores e condução, afim de diminuir os conflitos e gastos gerados com reformas de calçadas, assim como os riscos de queda.

Silva e Souza (2018) relatam que além da quebra de calçadas, há ocorrência de outros problemas associados ao mau ou falta de planejamento urbano no que diz respeito à arborização, relacionando a má qualidade da mesma (utilização de espécies exóticas, baixa diversidade, local de plantio inadequado, entre outros fatores), à infraestrutura urbana (rede elétrica, hidráulica, calçadas, sinalização de trânsito, etc.) resultando em prejuízos não só ao poder público, como também aos habitantes e à sua qualidade de vida.

Apesar das espécies encontradas no presente trabalho serem exóticas, tanto regionais (nativa do Brasil, mas em desacordo com o ecossistema local), quanto do país (Tabela 1), o cumprimento das Normas Brasileiras (NBRs) é, nesse caso, além da obrigatoriedade, também uma solução.

Segundo a NBR 9050/2015, as rotas de caminhamento para serem consideradas acessíveis devem ser trajetos contínuos, desobstruídos e sinalizados que podem conectar o ambiente e devem ser utilizadas de forma a promover a segurança e a autonomia de todas as pessoas, contudo o calçamento encontrava-se quebrado por toda sua extensão (Tabela 4). Dessa forma é necessário que seja realizada uma reforma do calçamento para melhoria da condição da via para a passagem da população.

Tabela 4. Situação do calçamento com relação à quebra do calçamento. Ilha Solteira, 2017. The situation of the pavement in relation to the breaking of the pavement. Ilha Solteira, 2017.

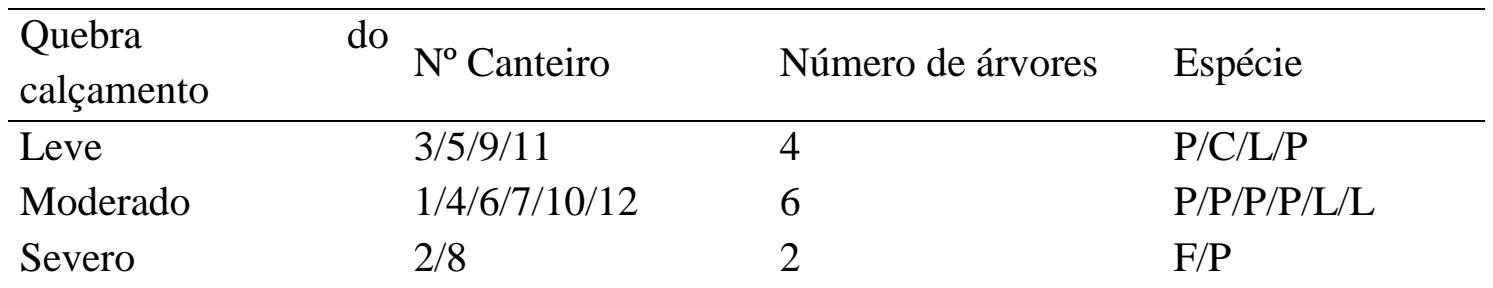

Notas: Espécie: C: Caesalpinea pulcherrima; F: Ficus benjamina; L: Licania tomentosa; P: Poincianella pluviosa. Leve (rachada, mas sem risco de gerar acidentes), moderada (calçada elevada com leve risco de colisão e que dificulta o passeio de pessoas com mobilidade reduzida), severo (pode ocasionar acidentes e impede o passeio de pessoas com mobilidade reduzida). Note: Species: F: Ficus benjamina; L: Licania tomentosa; P: Poincianella pluviosa. Light (cracked, but not dangerous to cause accidents), moderate (sidewalk high with slight risk of collision and that makes walking difficult for people with reduced mobility), severe (can cause accidents and prevents the walking of people with reduced mobility).

Fonte: Autoria própria. Own authorship.

Foram encontrados focos de cupim sendo que a espécie mais afetada foi Poincianella pluviosa (Sibipiruna), levando a supor que essas são mais susceptíveis do que as outras (Tabela 5). Milano (1988) relata que quando a presença de uma determinada espécie é maior 
do que $15 \%$ há aumento no risco de ocorrência de pragas e doenças, e, na situação em questão a espécie mais afetada representava $50 \%$ dos exemplares presentes.

Não foram encontrados fungos no caule das árvores, o que é positivo, visto que estes podem sinalizar risco de queda da árvore, posto que Brazolin et al. (2014) avaliando Tipuana tipu (Benth.) Kuntze na cidade de São Paulo, constataram relação entre a menor densidade, resistência e a rigidez da madeira e a presença de fungos xilófagos, sinalizando a biodeterioração do lenho. Assim, é imprescindível que sejam feitas vistorias com frequência avaliando as arvores para evitar a possibilidade da ocorrência de problemas como, por exemplo, a queda.

Tabela 5. Situação fitossanitária das árvores avaliadas. Ilha Solteira, 2017. Phytosanitary situation of evaluated trees. Ilha Solteira, 2017.

\begin{tabular}{llll}
\hline $\begin{array}{l}\text { Problemas } \\
\text { fitossanitários }\end{array}$ & $\mathrm{N}^{\mathrm{o}}$ Canteiros & Número de árvores & Espécies \\
\hline Cupim & $1 / 3 / 4 / 6$ & 4 & $\mathrm{P} / \mathrm{P} / \mathrm{P} / \mathrm{P}$ \\
Formigas & $3 / 4 / 12$ & 3 & $\mathrm{~L} / \mathrm{P} / \mathrm{P}$ \\
Fungos & - & - & - \\
\hline
\end{tabular}

Nota: Espécie: F: Ficus benjamina; L: Licania tomentosa; P: Poincianella pluviosa. Note: Species: F: Ficus benjamina; L: Licania tomentosa; P: Poincianella pluviosa.

Fonte: Autoria própria. Own authorship.

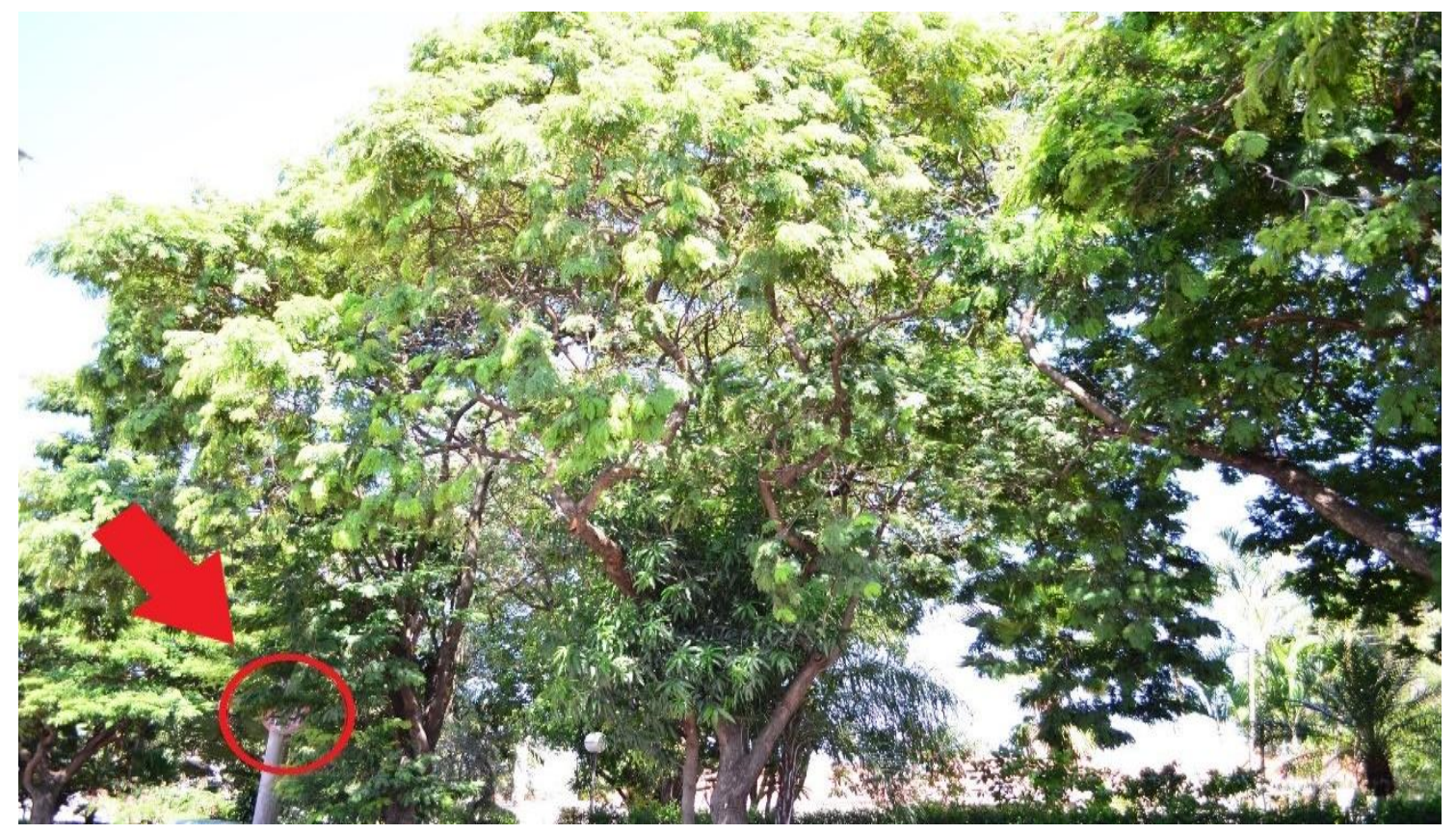

Figura 3. Presença de elementos de composição do paisagismo urbano. Ilha Solteira, 2017. Presence of urban landscape composition elements. Ilha Solteira, 2017.

Fonte: Autoria própria. Own authorship.

As análises visuais mostraram apenas a presença de "machucaduras" de podas que foram realizas a fim de suprimir alguns poucos galhos, visto que não ocorre a presença de fiação na região da área da copa das árvores, e assim não há problemas severos de poda ou destruição da copa natural das árvores, e as mesmas se desenvolvem de forma livre. Há presença de placa de velocidade (Figura 3) que está sem visibilidade, contudo esse empecilho 
pode ser resolvido por uma poda de elevação da copa, que segundo Silva Filho et al. (2018) consiste em selecionar e podar galhos para abrir espaços verticais.

\section{CONCLUSÃO}

O levantamento de espécies mostrou baixa diversidade ecológica; a calçada da área do estudo apresenta dimensões suficientes para possuir área de passeio e área livre para árvores conforme recomendações técnicas.

É necessário que as espécies escolhidas para arborização estejam de acordo com o bioma em que se encontra para que os problemas e o olhar pejorativo sobre as árvores sejam mitigados.

\section{AGRADECIMENTOS}

À Coordenação de Aperfeiçoamento de Pessoal de Nível Superior (CAPES).

\section{REFERÊNCIAS BIBLIOGRÁFICAS}

ALENCAR, L. D.; CARDOSO, J. C. Paisagismo funcional: o uso de projetos que integram mais que ornamentação. Revista Ciência, Tecnologia \& Ambiente, Araras, v. 1, n. 1, p.1-7, 2015.

ALVES, E.; SOUZA, G. S.; MARRA, R. Êxodo e sua contribuição à urbanização de 1950 a 2010. Revista de Política Agrícola, Brasília, v. 20, n. 2, p.80-88, 2011.

AMARAL, C. L.; PAVAN, G. B.; SOUZA, M. C.; MARTINS, J. V. F.; ALVES, P. L. C. A. Relações de interferência entre plantas daninhas e a cultura do grão-de-bico. Bioscience Journal, Uberlândia, v. 31, n. 1, p.37-46, 2015.

ASSOCIAÇÃO BRASILEIRA DE NORMAS TÉCNICAS. ABNT NBR 9050: Acessibilidade a edificações, mobiliário, espaços e equipamentos urbanos. 3. ed. Rio de Janeiro: ABNT, 2015. 148 p.

AVREllA, E. D.; WEILlER, E. B.; SILVA, A. C.; HIGUCHI, P. Avaliação qualiquantitativa da arborização urbana de praças e vias públicas. Revista de Ciências Agroveterinárias, Lages, v. 13, n. 3, p.227-237, 2014.

BRAZOLIN, S.; TOMAZELlO FILHO, M.; YOJO, T.; OLIVEIRA NETO, M. A.; ALBUQUERQUE, A. R.; SETTE JUNIOR, C. R. Propriedades físico-mecânicas do lenho deteriorado por fungos apodrecedores de árvores de Tipuana tipu. Revista Cerne, Lavras, v. 20, n. 2, p.183-190, 2014.

CABRAL, P. I. D. Arborização urbana: problemas e benefícios. Revista Especialize On-line, Goiânia, v. 1, n. 6, p.01-15, 2013.

COMPANHIA ENERGETICA DE MINAS GERAIS - CEMIG. Manual de arborização, Belo Horizonte: Fundação Biodiversitas, 2011. 112 p. 
COSTA, A. S. V. Por que as árvores caem mais nas zonas urbanas? Blog. [S. l.], 2018. Disponível em: https://agro2100.blogspot.com/2018/12/por-que-as-arvores-caem-mais-naszonas.html. Acesso em: 03 mar. 2019.

INSTITUTO BRASILEIRO DE GEOGRAFIA E ESTATÍSTICA - IBGE. Censo demográfico: séries históricas: censo 2010. Rio de Janeiro, 2018a. Disponível em: https://www.ibge.gov.br/estatisticas-novoportal/sociais/habitação/9662-censo-demografico2010.html?edicao=9755\&t=series-historicas. Acesso em: 23 set. 2018.

INSTITUTO BRASILEIRO DE GEOGRAFIA E ESTATÍSTICA - IBGE. Cidades IBGE: censo 2010. 2018b. Disponível em: https://cidades.ibge.gov.br/brasil/sp/ilhasolteira/panorama. Acesso em: 30 jan. 2019.

LIMA NETO, E. M.; BARDELLI-DA-SILVA, M. Y.; SILVA, A. R.; BIONDI, D. Arborização de ruas e acessibilidade no bairro Centro de Curitiba - PR. Revista da Sociedade Brasileira de Arborização Urbana, Piracicaba, v. 5, n. 4, p.40-56, 2010.

LONDE, P. R.; MENDES, P. C. A influência das áreas verdes na qualidade de vida urbana. Revista Brasileira de Geografia Médica e da Saúde, Uberlândia, v. 10, n. 18, p.264-272, 2014.

MARTELLI, A.; CARDOSO, M. M. Favorecimento da arborização urbana com a implantação do projeto espaço árvore nos passeios públicos do município de Itapira-SP. Revista de Geografia e Interdisciplinaridade, Grajaú, v. 4, n. 13, p.184-197, 2018.

MARTINS, L. F. V.; ANDRADE, H. H. B.; HANISCH, R. F.; DE ANGELIS, B. L. D.; CAXAMBU, M. G. Análise da compatibilidade da arborização viária com o ambiente construído na cidade de Luiziana, Paraná, Brasil. Revista da Sociedade Brasileira de Arborização Urbana, Piracicaba, v. 6, n. 3, p.103-127, 2011.

MILANO, M. S. Avaliação quali-quantitativa e manejo da arborização urbana: exemplo de Maringá - PR. 1988. 120 f. Tese (Doutorado em Engenharia Florestal) - Universidade Federal do Paraná, Curitiba, 1988.

PAIVA, A. V.; LIMA, A. B. M.; CARVALHO, A.; MIRANDA JUNIOR, A.; GOMES, A.; MELO, C. S.; FARIAS, C. O.; REIS, C.; BEZERRA, C., JUNIOR, E. A. S.; MACEDO, E.; LIMA, E. S.; SOBRINHO, F.; SILVA, F. M.; BONFIM, J. C.; JUNIOR, L. S.; CORREA, M.; DUMONT, M. L.; ISAAC JUNIOR, M. A.; PANTOJA, N. V.; DAVILA, R. M.; GABRIEL, R.; SILVA, R. A.; CUNHA, R. M.; OLIVEIRA, R. S.; DIAS, R.; NICHELI, S. R.; COSTA, S.; SOUZA, T. C.; PEREIRA, T. F.; CASTELO, Z.; FERRARI, Z. S. Inventário e diagnóstico da arborização urbana viária de Rio Branco, AC. Revista da Sociedade Brasileira de Arborização Urbana, Piracicaba, v. 5, n. 1, p.144-159, 2010.

PEREIRA, L. A.; LOBADA, C. R. Área verde urbana na forma de canteiro central: estudo sobre a Avenida Minas Gerais em Ituiutaba (MG). Revista Periódico Eletrônico "Fórum Ambiental da Alta Paulista". [S. l.], v. 13, n. 8, p.74-88, 2017.

RIZZARDI, M. A.; FLECK, N. G.; VIDAL, R. A.; MEROTTO-JUNIOR, A.; AGOSTINETTO, D. Competição por recursos do solo entre ervas daninhas e culturas. Revista Ciência Rural, Santa Maria, v. 31, n. 4, p.707-714, 2001. 
SANTOS, J. J. A.; SANTOS, A. E. S.; SILVA, A. M.; SANTOS, V. C.; SANTANA NETO, D. C. Levantamento botânico de plantas utilizadas na arborização urbana de Nova Palmeira, Paraíba. Revista Verde de Agroecologia e Desenvolvimento Sustentável, Pombal, v. 12, n. 5, p.866-873, 2017.

SANTOS, R. C.; BESSEGATO, D.; ANTUNES, L.; MALENGO, F. M. Análise qualiquantitativa da arborização urbana do centro da cidade de Sananduva-RS. Revista Gestão \& Sustentabilidade Ambiental, Florianópolis, v. 7, n. 2, p.143-158, 2018.

SILVA, S. T.; SOUZA, B. H. Diagnóstico da arborização urbana do munícipio de GuarabiraParaíba. Paisagem e Ambiente, São Paulo, n. 41, p.167-184, 2018.

SILVA FILHO, D. F.; POLIZEL, J. L.; OLIVEIRA, R. G. M. G.; GIALlUCA, V.; ROSÁRIO, U. F.; CAMARGO, C. D. F. Arborização urbana: guia para identificação, manejo e avaliação do risco de queda. Piracicaba: FEALQ, 2018. 119 p.

SÃO PAULO. Secretaria do Verde e do Meio Ambiente - SVMA. Manual Técnico de Arborização Urbana. 2. ed. São Paulo, 2011. Disponível em: http://arquivos.ambiente.sp.gov.br/municipioverdeazul/2011/11/ManualArborizacaoUrbanaPr efeituraSP.pdf. Acesso em: 05 nov. 2018.

SOUZA, V. F. O.; SANTOS, G. L.; RODRIGUES, M. H. B. S.; BARROSO, R. F.; BARBOZA, J. B.; FERNANDES, A. V. F. Percepção sobre a qualidade da arborização urbana da cidade de Pombal, Paraíba. Revista Verde de Agroecologia e Desenvolvimento Sustentável, Paraíba, v. 13, n. 3, p.343-347, 2018. 